To the Editors:

\title{
Accuracy of cause of death in hospital death declaration forms
}

Death declaration forms are legal records of death, necessary for burial or cremation of the dead and for medico-legal procedures concerning insurance and inheritance. As the forms include a section dealing with "cause of death", they can be used for compiling mortality statistics in medical research and health policy planning. In the section dealing with "cause of death" doctors are expected to certify (a) the immediate cause (b) antecedent and/or underlying causes and (c) contributory causes of death. We sought to determine whether the causes of death documented in death declaration forms issued at the Lady Ridgeway Hospital (LRH) accurately reflect the disease responsible for death.

Case notes of 128 children who died at LRH during a 5-month period commencing from May 2000 were analysed to identify the disease responsible for death. The counterfoils of the corresponding death declaration forms were reviewed to determine whether this disease was accurately documented. The cases were divided into 7 categories as shown in the table.

At present at the LRH, mortality statistics are complied by non-medical personnel, who scrutinise the case notes for the cause of death. This procedure is cumbersome and liable to error. It would be simpler to use the cause of death documented in the counterfoil of accurately certified death declaration forms. However, the results of this study show that the "cause of death" has not been accurately certified in $91.4 \%$ of these forms. A study at the General Hospital Colombo in 1986, showed that $38 \%$ of death certificates were accurately. recorded (1), although this study analysed only the format of recording of death declaration forms and case notes were not scrutinised to determine if the cause of death was accurately reflected.

The category "immediate cause of death" should not include modes of death such as cardio-respiratory arrest, asphyxia or coma (2). The certification of cardio-respiratory arrest as the immediate cause in $70 \%$ of cases in the present study shows that this is poorly understood. Pulmonary heart disease including disease of pulmonary circulation is listed as the fourth leading cause of hospital deaths in Sri Lanka (3). It is possible that some cases of cardio-respiratory arrest have been included this category. As in the British death declaration forms (2), Sri Lankan forms should include instructions not to include modes of death as causes. In the present study in $61.7 \%$ of cases, the disease process responsible for death was recorded under "underlying or antecedent cause of death". In view of these findings it could be argued that data collectors could ignore the category "immediate cause" if it includes a mode of death and use the "underlying or antecedent casue" as the cause of death. This raises the question whether the ambiguous term "immediate cause" needs to be included at all. The immediate events leading to death may be difficult to determine even in cases where patients had obvious diseases responsible for death. For the purpose of mortality statistics recording of the disease which would have most likely contributed to death is more meaningful than recording the immediate cause. Thus we recommend changing of the terminology of the section dealing with cause of death in the Sri Lankan death declaration forms as given below.

(a) Disease most likely to be responsible for death

(b) Underlying disease that could have contributed to death.

(c) Remove the category "immediate cause of death",

It has been suggested that doctors should be given training in accurate certification of deaths $(1,2,4)$. Al a time when medical faculties in Sri Lanka are modifying curriculums, it will be prudent to decide which Department or "module" should take over this responsibility.

Table. Analysis of accuracy of cause of death in death declaration forms

Category

1. Disease responsible for death accurately documented as cause of death

2. Disease responsible for death stated as underlying cause of death

3. Disease responsible for death stated as contributory cause

4. Disease responsible for death not stated at all

5. Certification of wrong cause of death

6. Disease responsible for death stated correctly but significant contributory causes omitted

7. Cause of death could not be determined
Number

11

79

21

6

5

2

4
$\%$

61.7

16.4

4.7

3.9

1.6

3.1 


\section{Research letters}

We thank the Director and all paediatricians at the LRH for giving us access to records.

\section{References}

1. Fernando R. Medical certification of casue of death in the General Hospital Colombo. Ceylon Medical Journal 1990; 35: 71-74.

2. Knight B. The coroner's autopsy; a guide to non-criminal autopsies for the general pathologist. Edinburgh: Churchill Livingstone, 1983; 53-60.

3. Department of Health Services of Sri Lanka. Annual Health Bulletin, 1999; 89.

4. Joint report of the Royal College of Physicians and the Royal College of Pathologists. Medical aspects of death certification. Journal of Royal College of Physicians of London 1982; 16: 205-218.

M V C de Silva', R D KS Gunaratne', D M D E A Gunerwardena ${ }^{3}$ and S P Lamabadusuriya4, 'Senior Lecturer, ${ }^{2.3}$ Demonstrators, Department of Pathology; and ${ }^{4}$ Professor and Head, Department of Paediatrics, Faculty of Medicine, University of Colombo.(Correspondence MVC de S, telephone +941645575, email: pradeepa@sri.lanka.net) 